\title{
A Questão do Consenso nas Representações Sociais: Um Estudo do Medo Entre Adultos
}

\author{
Antonio Roazzi ${ }^{1}$, Fabiana C. B. Federicci \\ Universidade Federal de Pernambuco \\ Maria do Rosário Carvalho \\ Universidade Federal do Rio Grande do Norte
}

\begin{abstract}
RESUMO: O presente estudo aborda a questão metodológica que caracteriza a pesquisa na área das representações sociais. Em particular, aprofunda o problema da verificação empírica do consenso que uma representação possui para um determinado grupo social. Esta preocupação metodológica foi abordada neste estudo cujo objetivo foi compreender a organização estrutural da representação social do medo em adultos de ambos os sexos. O interesse foi também analisar o papel do gênero na construção deste tipo de representação. Primeiramente, com um grupo de 60 indivíduos adultos, foi desenvolvida a abordagem da livre associação de idéias, como meio de acesso ao campo semântico das representações, (pedia-se que os sujeitos expressassem livremente o que pensavam com a evocação da palavra medo). A partir deste levantamento, foram selecionadas 20 palavras entre as mais evocadas. Depois, com um grupo de 72 sujeitos, foi investigado o nível de consenso da representação social do medo através da técnica não-verbal de classificação. Para tal investigação, os sujeitos foram submetidos a duas tarefas: uma de classificação livre, em que foram convidados a agrupar as 20 palavras inscritas nos cartões, mais a palavra "medo", em grupos diferentes de acordo com a similaridade de significados, ou de função, entre elas; a outra tarefa foi a de classificação dirigida: os sujeitos foram solicitados a pensar sobre as 20 palavras e ordená-las em função de estarem mais ou menos associadas com a emoção medo. Os dados foram analisados por métodos estatísticos multidimensionais (SSA, MSA). Considerados em seu conjunto os resultados das projeções MSA dos dois grupos de adultos - homens e mulheres - apresentam as mesmas regionalizações dos itens e um mesmo tipo de polarização entre as regiões. As várias regiões - Saúde, Abandono, Entidades Sobrenaturais e Violência Social - apresentam elementos e características qualitativamente diferentes, cada região ocupando uma direção no espaço da projeção MSA, que emana de um mesmo ponto comum de origem - o item "medo". O medo, portanto, é o elemento polarizador, em torno do qual se estruturam os demais. A Projeção SSA, considerando toda a amostra, apresentou a Saúde como a região central e as outras ao redor formando uma estrutura tipo "radex". Observou-se também que, de maneira geral, as mulheres apresentam médias superiores em relação aos homens, à exceção dos itens solidão, separação, escuro e menino de rua. Enfim, estes resultados são interpretados e discutidos em relação à investigação sobre as representações sociais focalizando o problema de sua verificação empírica.
\end{abstract}

Palavras-chave: medo; representações sociais; AIDS.

\section{Consensus in Social Representations: A Study of Fear in Adults}

\begin{abstract}
The study examines a methodological question that concerns research on social representations. In particular, it permits a deeper examination of the problem of the empirical validation of the consensus that a representation has among a particular social group. This methodological concern was approached in a study whose main aim was to understand to structural organisation of the social representation of fear among adults of both sexes. The elements of representation of fear were first collected from a group of 60 adults through a free association method which consisted of asking the subjects to say what they thought of when the word fear was used. 20 of the commonest responses were then selected. Another group of 72 adults then participated in a study where the level of consensus of the social representation of fear was investigated using one free and one guided non-verbal sorting task. Results of the MSA analysis of the free sort for both groups of adults, men and women, showed the same regional polar structure with respect to the conceptualisation of fear. The facet of fear was comprised of four qualitatively different elements: "Health", "Abandonment", "Supernatural Entities" and "Social Violence". Each one of these facets occupied a different direction in the space of the MSA plot, though emanating from the same common point of origin: the item "fear ". The SSA plot for the whole sample, showed that there is a central area for- "Health" (having the item AIDS at the very centre), and that the other areas form a radex structure around it. It was also observed that, in general, women presented higher mean fear scores than men, except for the items " "solitude", "separation", "darkness" and "street children". Finally, these results are interpreted and discussed in relation to the problem of the empirical validation of social representations.
\end{abstract}

Key Words: fear; social representation; AIDS.

1 Endereço: Rua Francisco da Cunha, 654/801, Ed. Villa das Pedras, Boa Viagem, 51020-041 Recife, Pernambuco. Telefone: (0xx81) 3467.5722 (Res.), 3271.0599 e 3271.8272 (Uni). Fax: (0xx81) 3271.1843. E-mail: roazzi@npd.ufpe.br 
A pesquisa sobre as representações sociais encontra-se em um momento de indagação que pede uma reflexão sobre si mesma, sobre questões metodológicas e, principalmente, sobre como gerar conhecimentos que representem a complexidade do problema (Roazzi, 1997).

As representações sociais, por serem elaboradas na fronteira entre o psicológico e o social, são capazes de estabelecer conexões entre as abstrações do saber e das crenças e a concretude da vida do indivíduo em seus processos de troca com os outros. Neste sentido, Moscovici (1961) refere-se à "pressão por inferência" como conseqüência da necessidade que os indivíduos têm de, continuamente, reagirem à dinâmica social. (p.361). Sendo assim, adotar o "construto" das representações sociais significa buscar compreender não somente o que e como as pessoas representam um objeto cujo conteúdo possui um valor socialmente evidente e relevante mas também por que e para que o fazem daquela forma. Nesta perspectiva emergem de forma nítida os sentidos dos processos de simbolização e da atividade cognitiva em relação aos significados que o mundo externo assume a nível da vida psíquica (Roazzi, Wilson \& Federicci, 1995).

Este artigo procura ir ao encontro destas preocupações $\mathrm{e}$, a partir de um questionamento sobre as metodologias utilizadas na pesquisa em representações sociais, apresenta uma reflexão sobre o consenso das representações. Qual o nível de consenso acerca dos significados relativos à natureza social da representação social? Qual o nível de consenso ou o compartilhar do qual uma determinada representação é objeto, em um determinado grupo ou grupos, que possibilite assim, comparações entre as representações que grupos diferentes fazem de um mesmo objeto (Galli \& Nigro, 1986; Le Bouedec, 1979; Monteiro \& Roazzi, 1987; Nigro \& Galli, 1988; Roazzi, 1997 1999, 2000; Roazzi \& Monteiro, 1991, 1995)? É preciso lembrar que as representações sociais, como as teorias científicas, as religiões e as mitologias, são sempre as representações de algo e de alguém (Moscovici, 1984). Nesta perspectiva, examinamos semelhanças e diferenças (áreas de consenso) em relação à emoção do medo entre adultos de ambos os sexos.

\section{Emoções e Estudos Sobre o Medo}

A emoção apresenta-se à consciência como um fenômeno imediato e concreto que carrega seu próprio sentido sem que o tenhamos solicitado. Devido à complexidade deste seu caráter subjetivo, demorou a se constituir em campo de investigação sistemática, permanecendo durante muito tempo restrito às análises clínicas. Uma das dificuldades encontradas para realizar estudos sobre a emoção é a incompatibilidade de enfoques; enquanto para alguns psicólogos ela deveria ser vista como um aspecto social do comportamento, que está imbuída de significados convencionais, para outros, ela seria produto de programas instintivos capazes de gerar afetos e movimentos expressivos em todos os seres humanos. Outro problema no estudo das emoções é a diversidade com que são designadas e encaradas em culturas diferentes, suscitando, certamente, dificuldades de compara- ção. Todavia, o construto das representações sociais permite um recorte epistemológico para a investigação relevante e factível da estruturação e representação social das emoções (Ades, 1993).

Para muitos, o medo é a emoção negativa mais comum; mais do que isso, sendo um dos mais fortes delineadores da personalidade das pessoas, influencia no que pensamos poder ou não fazer. Ele reage sobre si mesmo, conseqüentemente ficamos com medo dele mesmo (Ainsworth, 1981). Segundo Hersen (1973) o medo pode ser analisado a partir de três aspectos: (1) verbal, sendo que neste aspecto ele aparece como auto-relato, avaliação subjetiva do sujeito sobre seu medo; (2) motor, que se caracteriza pela reação comportamental-orgânica observável e medida; (3) psicológico. É justamente sobre este ultimo aspecto que se concentra nosso estudo.

Nossos medos alteram-se com idade, gênero, classe sócio-econômica, nível de desenvolvimento cognitivo e outras variáveis de natureza individual ou social (tais dados podem ser úteis para a determinação de quando um medo é normal ou patológico, consequentemente, quando uma intervenção é necessária). Dados de estudos antigos (Hallowell, 1938) sobre medo em adultos sugerem que as reações de medo podem ser grandemente influenciadas por variáveis de ordem cultural.

Nossos inúmeros temores servem a dois propósitos legítimos e úteis: primeiro, atuam como mecanismos de alerta, uma resposta de adaptação que serve para proteger os indivíduos de situações potencialmente perigosas (Ainsworth, 1981; Fonseca, 1993); além disso, a emoção libera e disciplina um fluxo de energia que pode ser empregado em qualquer ação que se faça necessária. E essa combinação é de grande importância para a sobrevivência biológica. O mesmo mecanismo psicológico também age em casos de medos de um tipo muito diferente, ou seja, a estrutura total do ego também deseja sobreviver, desenvolver-se ou expressar-se, então qualquer ameaça à livre satisfação destes desejos resulta quase sempre numa resposta de medo, o mesmo ocorrendo com uma ameaça de perda.

Mas como definir o medo? Segundo Ainsworth (1981), uma maneira simples de defini-lo é dizendo que este é a consciência de uma ameaça, que pode assumir inúmeras formas. Já Morris e Kratochwell (1983) definem o medo como uma reação emocional mais ou menos intensa perante um perigo específico, real ou imaginário.

Vê-se então que não é fácil definir o que vem a ser o medo, sendo isso uma evidência de sua complexidade. $E$ da mesma forma que é difícil defini-lo, o é para ser investigado. A maior parte do conhecimento nesta área tem se baseado em trabalhos efetuados em países de língua inglesa (Bauer, 1976; King, Gullone \& Ollendick, 1992; King Hamilton \& Ollendick, 1988; King, Ollier, Iacuone, Shuster, Bays, Gullone \& Ollendick; Marks, 1987; Ollendick, 1979, 1983; Ollendick \& King, 1991; Ollendick, King \& Frary, 1989; Ollendick, Yule \& Ollier, 1990; Scherer \& Nakamura, 1968). E estudos que tentam estabelecer padrões de incidência e evolução em outras populações e/ou culturas não são muito 
freqüentes (e.g., Dong, Yang \& Ollendick, 1993; Fonseca, 1993; Galli \& Nigro, 1986; Nigro \& Galli, 1988; Roazzi, Wilson \& Federicci, 1995). Uma das dificuldades com que freqüentemente se deparam os investigadores interessados nesta questão é a falta de instrumentos adequados que possam oferecer uma unidade avaliativa comum a diferentes locais e culturas (Fonseca, 1993).

Em resumo, pressupõe-se que o medo estrutura-se sob influência de fatores culturais, mas se questiona a abrangência desta influência com a hipótese de fatores universais do medo. Isto está longe de ser definido, e este também não é o objetivo do nosso trabalho, o qual é ampliar o conhecimento sobre as complexidades do medo e quais suas conceptualização e organização estrutural em adultos.

A emoção não consiste apenas em uma percepção de si próprio, mas também necessita do conhecimento da situação, dos eventos (ou representação destes) em que ocorrem, e o impacto dessa situação merece uma avaliação cognitiva. A emoção é percebida também pelos outros, suscita reações de sua parte e certamente isso tenha por função primordial a comunicação. Ela prepara e modula o comportamento levando o indivíduo a agir de modo a diminuir as experiências desagradáveis e prolongar os afetos positivos. Wallon (conforme citado em Dantas, 1994) demonstrou o poder que tem a função tônica (expressões faciais de emoções) de controlar o ambiente social antes que exista a possibilidade da ação clônica (movimentos) sobre os objetos do mundo físico. Com relação à avaliação das emoções, pode-se questionar que níveis de racionalidade fundamentam o sentimento. Zajonc (conforme citado em Ades, 1993) acredita que este envolvimento seja pequeno, pelo menos no que se refere ao primeiro impacto de um estímulo gerador de afeto.

Vê-se então que para compreendermos as dinâmicas do comportamento humano em sua complexidade é de fundamental importância o estudo das emoções. No que se refere à elaboração de novas perspectivas teóricas, podemos reconhecer duas categorias que são definidas a partir da ausência ou presença do fator cognitivo, sendo que o papel desempenhado por este fator, nos últimos anos, tem se tornado uma área muito explorada e discutida dentro da literatura. Mandler (1982) expressa essa preocupação de estabelecer conexões entre cognitivo e emocional dizendo que, da mesma forma que as do adulto, as emoções das crianças são construídas partindo de uma variedade de eventos, dentre os quais podemos encontrar aqueles de natureza cognitiva e aqueles de natureza visceral, a partir de sinais culturais e idiossincráticos, e de estruturas inatas e aprendidas.

Uma abordagem de tipo psicossocial pressupõe que, para compreender as ações humanas, deve-se considerar não apenas as estruturas e organizações cognitivas e suas formas de interação e combinação, mas também o conteúdo e as origens sociais das mesmas, uma vez que as emoções de um indivíduo não são governadas unicamente pelo êxito de suas ações, mas ainda pela antecipação da aprovação ou desaprovação que os outros manifestam em relação a ações que atendem ou não a determinadas regras ou normas (Harris, 1989).

As representações sociais, tomadas como sentido atri- buído aos objetos pelos sujeitos a partir de sua prática e de suas relações, vêm revelando seu grande potencial heurístico no campo de pesquisa. Pressupõe que a realidade é sempre vista a partir de um recorte, uma dimensão dela mesma, nunca em si mesma. Pressupõe também que a atividade simbólica é o grande articulador deste recorte, feito a partir dos sonhos, crenças, sensações, onde emoções e afetos emergem como mediadores tão significativos quanto pensamento e linguagem, ou os processos grupais. Desta perspectiva, podese vislumbrar as estruturas cognitivas como 'softwares' e, ao mesmo tempo, como (psico)lógicas, dotadas de inteligibilidade própria (Carvalho, 1997; Jodelet, 1989; Lane, 1993; Madeira \& Carvalho, 1997, 1998; Sawaia, 1993; Spink, 1993; Teves, 1992; Vygotsky, 1934).

Com base nestes fundamentos teóricos sobre as emoções e as representações, realizou-se este estudo cuja finalidade foi investigar a emoção do medo sob uma perspectiva psicossocial; foi também objetivo desse trabalho ampliar conhecimentos sobre a representação deste objeto entre crianças, onde também se realizou uma análise comparativa entre as que apresentavam experiências socioculturais bastante diferentes (Roazzi \& cols., 1995).Naquele estudo, apesar das diferenças específicas de cada grupo, não se encontraram diferenças acentuadas na representação social do medo, ou seja, essas diferenças não alcançaram significância estatística. Entretanto, deve-se considerar o fato de ser aquela pesquisa uma investigação isolada na área de estudos da representação social do medo. O presente trabalho, utilizando-se da mesma metodologia e do mesmo tipo de análise (SSA, MSA), teve o objetivo de analisar a estrutura da representação social do medo em adultos, bem como a dinâmica de relações entre os elementos estruturantes de tal maneira a clarificar o nível de consenso destas representações em função do gênero. Segundo Moscovici (1961), a busca do consenso, pelos indivíduos, decorre da pressão à inferência permanentemente exercida pelo grupo. Deste modo, o consenso permeia a comunicação, conferindo inteligibilidade própria ao grupo e exercendo influência nos julgamentos dos indivíduos sobre objetos sociais. Tais julgamentos, portanto, supõem a seleção de informações para além da pura constatação destas.

\section{Questão Metodológica}

A escolha da metodologia de pesquisa foi, em grande parte, influenciada pelas críticas teóricas à forma de coletar e analisar os dados e, principalmente, pelas técnicas analíticas disponíveis para lidar com este tipo de dados. Dois fatores principais levaram à escolha dos métodos de análise: (1) a natureza essencialmente qualitativa dos dados, que requer o uso de um tipo de estatística não-paramétrica, e (2) a natureza do assunto em estudo, que necessita de procedimentos estatísticos que mantenham a integridade dos dados. Neste sentido, toda a gama de análises multidimensionais nãométricas tem demonstrado ser bem adequada para atender a estas duas exigências (Shepard, 1962; Schiffman, Reynolds \& Young, 1981; Shye, 1978; Souza, 1988). 
Dado que estes tipos de análises estão baseados em processos de categorização, adotando principalmente técnicas não verbais, que encontram suas raízes nas origens da própria psicologia, especialmente da cognitiva e da social, estes esclarecimentos vertem sobre a emergência de sistemas conceituais e sua relação com o processo de categorização.

\section{Sistemas Conceituais e Categorias}

Sabemos que os procedimentos de investigação que privilegiem aspectos qualitativos permitem uma maior aproximação da visão de mundo dos sujeitos. $\mathrm{O}$ foco de interesse do pesquisador está, de maneira geral, nas formas como os indivíduos pensam, sentem e se comportam com relação a importantes fatos e experiências da vida. Esta forma de ação e conceituação do mundo - pelo sujeito - reflete-se nos sistemas de classificação e de categorização do mesmo (Roazzi, 1995). Por outro lado, tais sistemas estruturam as ações e conceituações dos indivíduos.

Em psicologia, não é novidade que a maneira como os indivíduos conceituam o mundo que lhes circunda está relacionada, diretamente ou não, com as lógicas de categorizar e de construir sistemas de classificação pelos quais estímulos diferentes possam ser tratados como equivalentes (Kelly, 1955). De fato, o significado que o indivíduo possui do mundo que está à sua volta é construído sobre uma rede de categorizações. Tajfel (1981) afirma: "O papel da categorização em percepção e em outras atividades cognitivas tem desempenhado, durante muito anos, um papel fundamental na formulação de teorias em psicologia" (p. 305). A compreensão da forma como as pessoas categorizam e atribuem conceitos às categorizações é uma questão central para que possamos responder ao seguinte questionamento: Qual a natureza dos conceitos que as pessoas formulam e como estes conceitos são organizados nas relações com o mundo e com os outros?

Deste modo, a compreensão das categorias a partir das quais o indivíduo ordena seu mundo e os conceitos que a este atribui é fundamental para que se alcance os sentidos e os significados subjacentes.

Um dos procedimentos adequados para explorar as estratégias pelas quais as pessoas categorizam e elaboram sistemas de classificação é o Procedimento de Classificações Múltiplas (PCM) (para maiores detalhes ver Roazzi, 1995). Esta metodologia de investigação deriva-se dos procedimentos de categorias-próprias de Sherif e Sherif (1969) e das tarefas de classificação elaboradas por Vygotsky (1934). E vem se consolidando como metodologia apropriada para pesquisa de sistemas conceituais em várias áreas da psicologia, como, por exemplo, a psicologia social (Eckman, 1975; Tajfel, 1981) e a psicologia ambiental (Canter \& Comber, 1985; Groat, 1982).

O PCM pressupõe que o indivíduo já possua um conhecimento estruturado do mundo em que se encontra: deste modo, o que caracteriza cada estrutura ou categoria é a relação conceitual entre os elementos pertencentes a esta estrutura. A partir do exame de quais categorias e de como as pessoas as utilizam quando interagem com objetos do seu mundo, pode-se compreender de que maneira os concebem e os conceituam.

O PCM, além de enfatizar o aspecto qualitativo das categorias, enfoca também o processo de construção do sistema de classificação que medeia as relações dos indivíduos com o mundo complexo em que atuam. Este procedimento, por excelência, permite a exploração de sistemas conceituais tanto a nível individual como grupal. De fato, classificar, categorizar e convencionar são faces de um mesmo processo que permite a todos saberem "o quê denota o quê", e estão presentes em todas as nossas atitudes, ações e comunicações. As categorias e os conceitos encontram-se em relação de interdependência mutuamente estruturantes. Ao classificar objetos, o indivíduo seleciona aspectos relevantes destes, os quais passam a se constituir em categorias que possibilitam, por sua vez, a elaboração conceitual compatível com tais aspectos selecionados. A posse de um novo conceito, ao mesmo tempo, permite a (re)visão do objeto e nova categorização.

Nesta altura, é importante fazer uma distinção entre "processos de categorização e explicações ordinárias" que as pessoas dão às suas ações. Estas últimas decorrem de racionalizações após as quais o indivíduo verbaliza a resposta politicamente correta que supõe ser esperada de si a partir do que representa sobre seu interlocutor. No decorrer de um processo de categorização, ao contrário, o indivíduo atua sem censura e, quando fala, não está organizando sua mensagem para interlocutor, mas está "pensando alto". Este tipo de verbalização é a "fala interior" a partir da qual o pensamento é continuamente organizado (Vygotsky, 1934). De fato, a compreensão do sistema de categorização de uma pessoa e a forma com que estas categorias são sintetizadas em conceitos constituem a chave central para o entendimento das ações humanas.

É importante também notar que o processo de classificações envolve exNperiências cognitivas e afetivas com os objetos, e que o último elemento (afetividade) tem sempre um papel preponderante no processo. Deste modo, as formas como as pessoas classificam não se constituem em fenômeno estático ou uniforme por sua própria natureza, mas varia consideravelmente em forma e intensidade, dependendo do tempo, do espaço e das relações estabelecidas.

Na pesquisa com classificações livres, este procedimento requer do entrevistado que indique categorias a certos objetos de acordo com características que acha que possuam. Poucas são as limitações e nenhuma exigência é feita quanto à maneira de processar a classificação. No caso de classificações dirigidas, sugere-se somente o critério, mas o número de elementos em cada grupo, o número de grupos etc., são decisões do sujeito e não do pesquisador. Assim, uma outra vantagem deste procedimento é não limitar o sujeito na sua tarefa de formar categorias a partir dos elementos apresentados, podendo o sujeito lançar mão de diferentes critérios formulados por ele mesmo ou sugeridos pelo pesquisador. Neste procedimento, da mesma forma que nas entrevistas, procura-se identificar as categorias conceituais 
do entrevistado e as suas classificações dos elementos. Quanto maior for a liberdade dada ao entrevistado mais provavelmente o entrevistador irá apreender o sistema conceitual do sujeito.

Face à abordagem teórico-metodológica aqui delineada, nossa investigação enfocou a organização estrutural do medo em adultos, cujo enfoque requereu um procedimento que permitisse penetrar tais sistemas conceituais bem como os conjuntos subjacentes de regras utilizados para classificar situações, personagens e eventos. Para tal estudo, entrevistaram-se 72 sujeitos, de nível sócio-econômico médio, de ambos os sexos.

\section{Método}

\section{Participantes}

Fase 1 - Estudo de associação livre: nesta primeira fase participaram 60 indivíduos de ambos os sexos, com idade superior a 18 anos.

Fase 2 - Estudo de classificação livre e dirigida: a amostra de participantes que foram entrevistados nesta segunda fase continha 72 indivíduos adultos de nível sócio-econômico médio, numa faixa etária entre 20 e 39 anos de idade, sendo 34 do sexo masculino e 38 do sexo feminino.

\section{Material}

O material para a investigação consistiu de 20 cartões de $3 \times 4 \mathrm{~cm}$., cada um contendo a inscrição de um item daqueles selecionados por estarem freqüentemente mais associados com a palavra-estímulo medo, mais um cartão de igual tamanho dos demais, contendo a inscrição "medo"; este cartão só foi utilizado na primeira etapa da segunda fase do procedimento, na classificação livre.

\section{Procedimento}

\section{Associação livre}

Nesta primeira, os sujeitos (fase 1 ) foram convidados a expressarem de forma livre o que passava em suas mentes a evocação da palavra-estímulo medo e, assim, levantou-se a componente informação da representação entendida como meio de acesso ao campo das representações. Os itens selecionados foram os seguintes:

\begin{tabular}{ll}
\hline 01. Diabo & 11. Acidente de trânsito \\
02. Bruxa & 12. Solidão \\
03. Fantasma & 13. Velhice \\
04. Feitiçaria & 14. Menino de rua \\
05. Escuro & 15. Polícia \\
06. Morte & 16. Separação \\
07. Doença & 17. Desemprego \\
08. AIDS & 18. Assaltante \\
09. Dor & 19. Seqüestro \\
10. Sangue & 20. Violência sexual \\
\hline
\end{tabular}

Estes 20 itens integraram a tarefa de classificação para reconstruir o campo semântico e a estrutura da emoção medo. Cada sujeito realizou, individualmente, uma tarefa de classificação livre e, em seguida, uma de classificação dirigida.

\section{Classificação livre}

Nesta etapa do procedimento, foi solicitado ao sujeito que classificasse em grupos os cartões com as palavras-estímulo, de modo a termos, em cada grupo, elementos semelhantes, ou que conjugassem para um determinado fim. Os sujeitos foram livres para alocarem quantas palavras quisessem num mesmo grupo como também para formarem quantos grupos achassem necessários. Se por acaso o sujeito demonstrasse dúvidas em relação à tarefa, o experimentador apresentava um exemplo utilizando outros estímulos, como no exemplo abaixo:

Considere, por exemplo, que nós tenhamos estes três animais de brinquedo: um urubu, um cavalo e um leão. Se você tiver que fazer um grupo com dois deles, aqueles que se assemelham por alguma característica em comum, quais você colocaria juntos e qual seria o diferente dos outros dois?

Assim que o sujeito formava os grupos, o experimentador tomava nota dos componentes de cada um dos grupos. Finalizada a classificação, o pesquisador pedia ao sujeito que observasse bem a formação dos grupos e verificasse se estava satisfeito com aquela organização:

Você está contente com estes grupos e com as palavras em cada grupo? Se quiser, pode mudar estas palavras entre os grupos até estar satisfeito com o resultado.

Finalmente o investigador perguntava qual o motivo que tinha levado o sujeito a formar cada um dos grupos:

\section{Por que estas palavras estão neste grupo? O que elas têm em} comum?

O experimentador registrava o critério norteador da classificação assim como os comentários apresentados pelos sujeitos para uma compreensão do significado de cada agrupamento. Tomava nota destes conteúdos e dos números das palavras-estímulo alocadas a cada grupo caso houvesse modificações.

\section{Classificação dirigida}

Depois da classificação livre, através do mesmo procedimento básico, o entrevistador pedia ao sujeito para classificar as palavras-estímulo em função delas estarem associadas com a sensação de medo. A instrução específica para estas classificações era a seguinte:

\footnotetext{
Agora eu quero que você considere novamente estas mesmas palavras e, como antes, classifique-as ou as ordene em grupos. Mas, desta vez, eu vou dizer o critério pelo qual você vai classificar estas palavras. Em primeiro lugar, gostaria de que você pensasse sobre estas palavras que estão escritas nestes
} 
cartões e que as ordene em grupos em função de estarem mais associadas com a sensação de medo. A questão é: Quais das ações abaixo estão mais associadas com esta sensação? Quais estão menos associadas? Quais não estão associadas? Mais especificamente, eu quero que você separe estas palavras em vários grupos, dependendo do fato destas estarem mais ou menos associadas com esta sensação.

Para a execução desta etapa, o experimentador colocou em ordem decrescente cinco cartões que diferiam entre si pelo tamanho. E, nesta ordem, cada cartão representava um grau de associação com a palavra medo, sendo assim as palavras classificadas com base nos seguintes critérios: palavras muitíssimo associadas com o medo (escore 5); palavras muito associadas com o medo (escore 4); palavras mais ou menos associadas com o medo (escore 3); palavras pouco associadas com o medo (escore 2) e palavras não associadas com o medo (escore 1).

\section{Resultados}

\section{Classificação livre}

Os dados da classificação livre foram analisados através do MSA, pois este compara as categorias utilizadas por cada participante para cada item sem pressupor similaridade entre o significado das categorias e o mesmo número. Desta forma, um perfil para cada item é estabelecido tendo como base o nível de similaridade do número de categorias ao longo de cada linha (as linhas são formadas pelos itens; as colunas são formadas pelos sujeitos). O programa procura situar os itens de tal maneira que estes são classificados de acordo com uma categoria e estão representados em uma região facilmente identificável. Em seguida, eles são projetados em um espaço bidimensional de acordo como o princípio de contiguidade (Roazzi, Wilson \& Federicci, 1995).

Em nossa investigação os vinte itens utilizados na classificação foram selecionados a partir de uma associação livre com a emoção medo, como já foi especificado na metodologia. Então, é lícito supor que estes itens já estejam correlacionados de alguma forma com o item "medo". Sendo assim, a configuração espacial de uma classificação livre dos vinte itens, mais o item "medo", implica que a configuração do MSA seja de tipo "radex" tendo no centro o item "medo".

As Figuras 1 e 2, mostrando o resultado do MSA com base nas classificações livres dos homens e das mulheres, confirmam esta hipótese, pois podemos distinguir claramente quatro regiões bem distintas em volta do item "medo" formando uma estrutura tipo "radex" tanto para as mulheres como para os homens. O que se torna interessante é ver quais itens constituem cada uma das regiões e como se relacionam entre si e com a região central ocupada pelo item "medo". Na região superior, lado direito, é possível observar uma primeira região composta pelos itens "violência sexual", "assaltante", "polícia", "seqüestro", "acidente de trânsito", "menino de rua", "desemprego". Esta região é toda composta por características da barbárie das relações sociais e foi denominada de Violência Social. Do ponto de vista

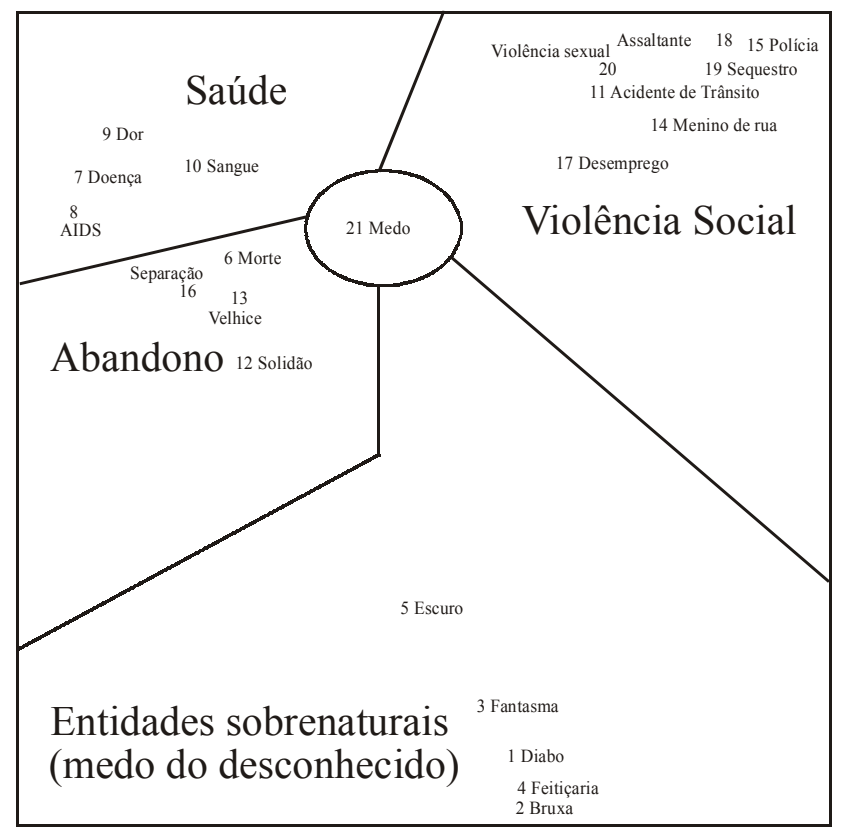

Figura 1. Análise MSA dos homens

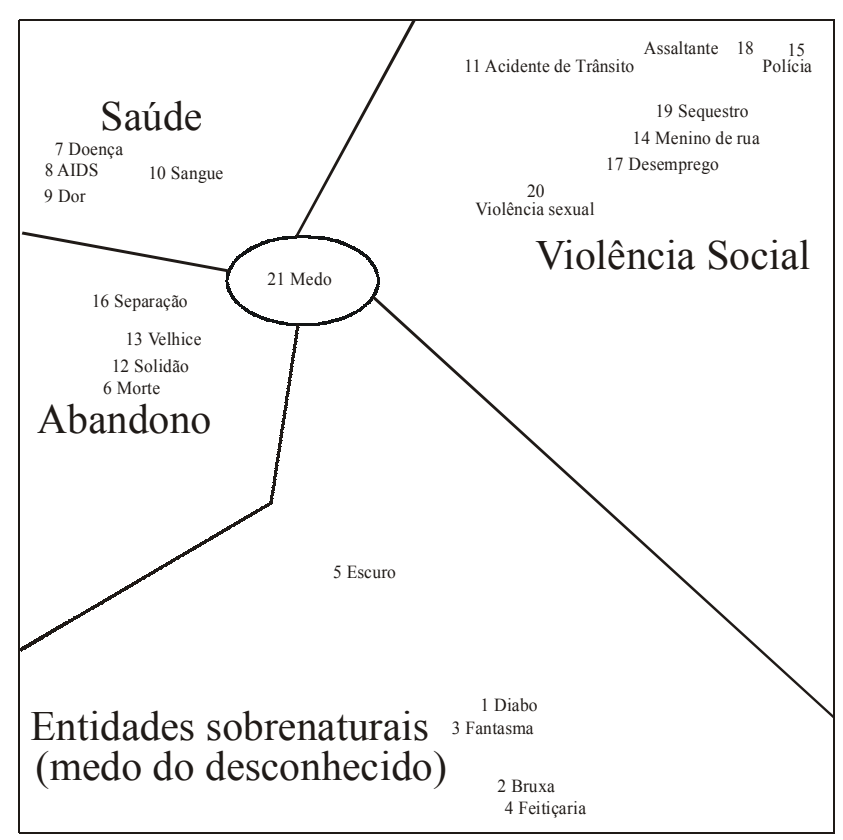

Figura 2. Análise MSA das mulheres

da localização, é a terceira região mais próxima do item "medo".

Na parte inferior, lado direito de ambas as Figuras, encontramos uma outra região composta pelos itens "bruxa", "feitiçaria", "fantasma", "escuro" e "diabo". Esta região é composta por entidades que devem fazer parte do universo simbólico das pessoas, dependendo de suas crenças, valores e símbolos. Por isso, foi denominada de Entidades Sobrenaturais. Nesta região, o item "escuro" encontra-se um pouco afastado dos outros, na direção da parte superior da Figura ocupada pela região Abandono (esse comportamento é observável para ambos os sexos). Esta região recebeu tal 
denominação por conter os itens "velhice", "separação", "solidão", "morte" e "medo". É a região mais central da projeção a partir do item central o "medo".

Na parte superior, lado esquerdo, é possível observarmos uma outra região composta pelos itens "dor", "doença", "sangue" e "AIDS". O que caracteriza esta região é que os itens que a compõem estão relacionadas com o bem estar orgânico das pessoas, portanto chamamos esta região de Saúde.

Pela configuração espacial das quatro regiões em relação ao item "medo", a região Entidades Sobrenaturais é a que se localiza mais afastada deste item, tanto para os homens como para as mulheres. Ao mesmo tempo as regiões Abandono, Saúde e Violência Social encontram-se muito mais próximas da emoção medo, principalmente as regiões Saúde e Abandono, sendo seguidas pela região Violência Social.

Se compararmos estas regiões, veremos que Abandono e Saúde são ao mesmo tempo as mais próximas entre si e as mais próximas do item "medo". Para ambos os grupos, a região Entidades Sobrenaturais encontra-se eqüidistante das demais. Uma variação entre os dois grupos é que na região Violência Social, para as mulheres, o item Violência Sexual se deslocou "destacadamente" dentre os demais, em direção ao item "medo", enquanto que, entre os homens, destacouse o item "desemprego". Vemos diferenças com relação à localização de alguns itens entre os grupos (homens e mulheres). Vemos que os itens "desemprego", "menino de rua" e "acidente de trânsito", para os homens, são os itens que mais se aproximam da região central, enquanto que, entre as mulheres, isso se dá com os itens "violência sexual", "de- semprego" e "menino de rua". Os demais itens desta região apresentam posições bastante semelhantes.

No grupo Saúde, para ambos os sexos, o item "sangue" se desloca em direção ao item "medo", como se deu com os itens "violência sexual" e "desemprego" no grupo Violência Social. Os demais itens do grupo Saúde mostram uma maior proximidade entre si, sendo esta mais acentuada nas mulheres.

\section{Classificação dirigida}

Nas classificações livres, analisadas através do MSA, exploramos qual tipo de regionalização os vinte itens assumiram e a relação destas regiões com o medo a partir de uma análise de perfis. Na classificação dirigida, nosso objetivo foi entender com mais detalhes a estrutura das relações entre estas regiões e destas com o "medo". O tipo de partição do SSA nos oferece evidências empíricas da estruturação do medo. Na Tabela 1 estão descritas as categorizações dos vinte itens realizadas pelo grupo dos homens e pelo das mulheres (médias, desvios-padrão e análise comparativa das medias através do teste estatístico Kruskal-Wallis).

Observa-se que, de um modo geral, as médias dos itens são mais elevadas no grupo das mulheres do que no dos homens, à exceção dos itens "velhice", "dor" e "polícia", que possuem médias mais elevadas para os homens. Percebe-se também, numa visão global, que estas médias se assemelham. Todavia, alguns itens merecem destaque, como é o caso do item "separação", cuja média encontrada no grupo das mulheres (3.66) é significativamente superior à encontrada entre os homens $\left(2.65 ; \chi^{2}=10.99, p<.01\right)$. O item

Tabela 1. Médias, desvios-padrões, médias ordenadas das categorizações dos itens pelos homens e pelas mulheres e valores $d e \mathrm{c}^{2} \mathrm{e} P$ da análise de KruskalWallis das comparações

\begin{tabular}{|c|c|c|c|c|c|c|c|c|}
\hline \multirow[t]{2}{*}{ Itens } & \multicolumn{3}{|c|}{ Homens } & \multicolumn{3}{|c|}{ Mulheres } & \multicolumn{2}{|c|}{ Kruskal-Wallis } \\
\hline & Média & $D P$ & MO & Média & $D P$ & MO & $\chi^{2}$ & $P$ \\
\hline 01. Diabo & 1.59 & .89 & 32.44 & 2.37 & 1.68 & 40.13 & 3.04 & .0812 \\
\hline 02. Bruxa & 1.44 & .70 & 35.13 & 1.77 & 1.19 & 37.72 & .38 & .5387 \\
\hline 03. Fantasma & 1.50 & .82 & 35.76 & 1.68 & 1.09 & 37.34 & .19 & .6659 \\
\hline 04. Feitiçaria & 1.41 & .66 & 34.54 & 1.84 & 1.33 & 38.25 & .79 & .3752 \\
\hline 05. Escuro & 1.50 & .89 & 31.82 & 2.08 & 1.30 & 40.68 & 4.00 & .0454 \\
\hline 06. Morte & 2.91 & 1.40 & 35.50 & 3.08 & 1.60 & 37.39 & .15 & .6941 \\
\hline 07. Doença & 3.70 & 1.31 & 34.76 & 3.89 & 1.27 & 38.05 & .48 & .4859 \\
\hline 08. AIDS & 3.59 & 1.58 & 33.38 & 4.00 & 1.56 & 39.29 & 1.77 & .1835 \\
\hline 09. Dor & 3.76 & 1.02 & 37.66 & 3.60 & 1.22 & 35.46 & .21 & .6429 \\
\hline 10. Sangue & 2.15 & 1.05 & 37.28 & 2.18 & 1.33 & 35.80 & .10 & .7548 \\
\hline 11. Acidente transito & 3.23 & 1.07 & 33.07 & 3.58 & 1.29 & 39.57 & 1.83 & .1758 \\
\hline 12. Solidão & 2.88 & 1.32 & 29.85 & 3.71 & 1.35 & 42.45 & 6.81 & .0091 \\
\hline 13. Velhice & 2.65 & 1.35 & 38.94 & 2.37 & 1.38 & 34.32 & .93 & .3338 \\
\hline 14. Menino de rua & 1.94 & 1.04 & 29.69 & 2.74 & 1.29 & 42.59 & 7.35 & .0067 \\
\hline 15. Polícia & 2.44 & 1.33 & 40.85 & 1.92 & 1.15 & 32.61 & 3.09 & .0789 \\
\hline 16. Separação & 2.65 & 1.23 & 28.10 & 3.66 & 1.17 & 44.01 & 10.99 & .0009 \\
\hline 17. Desemprego & 2.76 & 1.39 & 34.51 & 3.00 & 1.35 & 38.28 & .61 & .4353 \\
\hline 18. Assaltante & 3.44 & 1.13 & 32.06 & 3.92 & .94 & 40.47 & 3.15 & .0758 \\
\hline 19. Seqüestro & 3.18 & 1.51 & 33.66 & 3.55 & 1.41 & 39.04 & 1.25 & .2635 \\
\hline 20. Violência sexual & 2.79 & 1.36 & 25.15 & 4.24 & 1.08 & 46.66 & 20.27 & .0000 \\
\hline
\end{tabular}


"solidão" também possui diferença significativa entre as médias $\left(\chi^{2}=6.81 p<.01\right)$ onde, neste caso, o valor encontrado para a do grupo dos homens é inferior (2.88) ao encontrado para o das mulheres (3.71). Os itens que também possuem diferenças altas entre as médias, semelhante à encontrada nos itens "solidão" e "separação", são "escuro", cuja média para o grupo dos homens (1.50) é inferior à do grupo das mulheres (2.08), possuindo então diferença significativa $\left(\chi^{2}\right.$ $=4.00, p<.04)$, e "menino de rua", sendo que para este item a média para o grupo dos homens $(1,94)$ é inferior à encontrada para o das mulheres (2.74), diferença esta que também se mostrou significativa $\left(\chi^{2}=7.35, p<.01\right)$. Se analisarmos as médias por grupo, veremos que, para os homens, os itens que apresentam as cinco maiores médias foram, em ordem decrescente: "dor", "doença", "AIDS", "assaltante" e "acidente de trânsito"; enquanto que, para as mulheres, encontramos os itens em ordem decrescente: "violência sexual", "AIDS", "assaltante", "doença" e "separação". Se fizermos o mesmo exercício com as cinco médias mais baixas, teremos, para os homens, os itens na seguinte ordem: "feitiçaria" (média mais baixa), "bruxa", "fantasma", "escuro" e "diabo", e, para as mulheres, os itens na seguinte ordem: "fantasma" (média mais baixa), "bruxa", "feitiçaria", "polícia" e "escuro".

Percebemos então que em relação aos itens que menos causam medo, tanto em homens como em mulheres, estes são basicamente os mesmos, a maioria deles pertencente à região Entidades Sobrenaturais. Desse modo, podemos dizer que os itens desta região são os que menos amedrontam as pessoas e mostram o quão relacionados eles se encontram, pois, com exceção do item "polícia", que no grupo das mulheres pertence ao grupo dos cinco itens causadores de menor medo, os demais pertencem à região Entidades Sobrenaturais.
A esse respeito podemos dizer que, apesar das semelhanças entre os grupos, cada um possui características específicas. Vimos que, para as mulheres, o item "violência sexual" apresenta-se como o causador de maior medo, enquanto que, para os homens, é o item "dor". Além do mais, nos homens, o item que menos causa medo é "feitiçaria", enquanto que nas mulheres é o "fantasma". Estes itens apresentaram, nos respectivos grupos, as menores médias. Outro aspecto específico dos grupos é que, nos homens, o item "acidente de trânsito" é causador de medo, sendo ele o quinto elemento que mais amedronta. Já no grupo das mulheres, o item "separação" é causador de medo. Vimos que a diferença das médias para este item é significativa, o que reforça a idéia de que as mulheres se atemorizam mais com a possibilidade de sofrerem/passarem por algum tipo de separação.

Na Figura 3 são apresentados os resultados da classificação dirigida analisada através do SSA considerando toda a amostra. A matriz de correlação Kendall's Tau(b), que produziu esta projeção, encontra-se na Tabela 2. Nesta projeção, é possível observarmos a existência de cinco regiões, sendo que a quinta é um desmembramento da região Violência Social, que também encontramos na classificação livre.

Sobre a Figura 3 podemos dizer que, das cinco regiões encontradas, uma delas é central, tendo as demais ao seu redor. Desta forma temos uma estrutura tipo "radex". Observa-se uma região que podemos denominar de Saúde na área central da projeção; esta região é composta pelos itens "escuro", "morte", "AIDS", “doença" e "sangue". Nesta região Saúde temos o item AIDS como elemento central; o item "morte" encontra-se muito próximo da região Entidades Sobrenaturais (formada pelos itens "escuro", "diabo", "feitiçaria", "fantasma" e "bruxa"), tendo estas duas regiões como elemento comum o item "escuro"; portanto, sobre este

Tabela 2. Matriz do Coeficiente de Correlação de Kendall - Tau (b) entre os vinte itens considerando toda a amostra

\begin{tabular}{|c|c|c|c|c|c|c|c|c|c|c|c|c|c|c|c|c|c|c|c|}
\hline Itens & 01 & 02 & 03 & 04 & 05 & 06 & 07 & 08 & 09 & 10 & 11 & 12 & 13 & 14 & 15 & 16 & 17 & 18 & 19 \\
\hline 01. Diabo & - & & & & & & & & & & & & & & & & & & \\
\hline 02. Bruxa & .52 & - & & & & & & & & & & & & & & & & & \\
\hline 03. Fantasma & .37 & .66 & - & & & & & & & & & & & & & & & & \\
\hline 04. Feitiçaria & .43 & .73 & .56 & - & & & & & & & & & & & & & & & \\
\hline 05. Escuro & .29 & .24 & .41 & .23 & - & & & & & & & & & & & & & & \\
\hline 06. Morte & .20 & .16 & .30 & .26 & .36 & - & & & & & & & & & & & & & \\
\hline 07. Doença & .07 & .13 & .21 & .21 & .23 & .32 & - & & & & & & & & & & & & \\
\hline 08. AIDS & .24 & .23 & .28 & .31 & .35 & .31 & .45 & - & & & & & & & & & & & \\
\hline 09. Dor & -.03 & -.02 & .00 & .14 & .02 & .05 & .47 & .19 & - & & & & & & & & & & \\
\hline 10. Sangue & .13 & .16 & .25 & .15 & .21 & .18 & .28 & .20 & .20 & - & & & & & & & & & \\
\hline 11. Ac. tran. & .19 & .16 & .15 & .23 & .25 & .14 & .25 & .38 & .32 & .21 & - & & & & & & & & \\
\hline 12. Solidão & .17 & .25 & .14 & .25 & .22 & .01 & .26 & .25 & .17 & .12 & .15 & - & & & & & & & \\
\hline 13. Velhice & .04 & -.03 & -.07 & .00 & -.00 & .05 & .19 & .03 & .20 & .11 & .20 & .16 & - & & & & & & \\
\hline 14. Men. rua & .13 & .20 & .26 & .25 & .25 & .08 & .17 & .26 & .03 & .06 & .18 & .09 & -.03 & - & & & & & \\
\hline 15. Polícia & -.00 & -.00 & .17 & .08 & .05 & .03 & .08 & .14 & .19 & .15 & .30 & .06 & .03 & .04 & - & & & & \\
\hline 16. Separação & .15 & .14 & .13 & .17 & .18 & .08 & .17 & .14 & .29 & .09 & .27 & .46 & .12 & .19 & .00 & - & & & \\
\hline 17. Desemprego & .23 & .00 & -.01 & .01 & .11 & .04 & .23 & .35 & .30 & .19 & .48 & .12 & .14 & .15 & .20 & .10 & - & & \\
\hline 18. Assaltante & .19 & .00 & .01 & .10 & .06 & .21 & .34 & .26 & .29 & .04 & .25 & .20 & .12 & .26 & .14 & .24 & .32 & - & \\
\hline 19. Sequestro & .31 & .23 & .17 & .24 & .27 & .16 & .13 & .18 & .20 & .11 & .24 & .08 & -.05 & .24 & .16 & .07 & .42 & .34 & - \\
\hline \multirow[t]{2}{*}{ 20. Viol. sex. } & .26 & .07 & .11 & .12 & .22 & .21 & .26 & .36 &. .08 & .02 & .28 & .24 & -.04 & .14 & .04 & .23 & .29 & .37 & -.39 \\
\hline & 01 & 02 & 03 & 04 & 05 & 06 & 07 & 08 & 09 & 10 & 11 & 12 & 13 & 14 & 15 & 16 & 17 & 18 & 19 \\
\hline
\end{tabular}




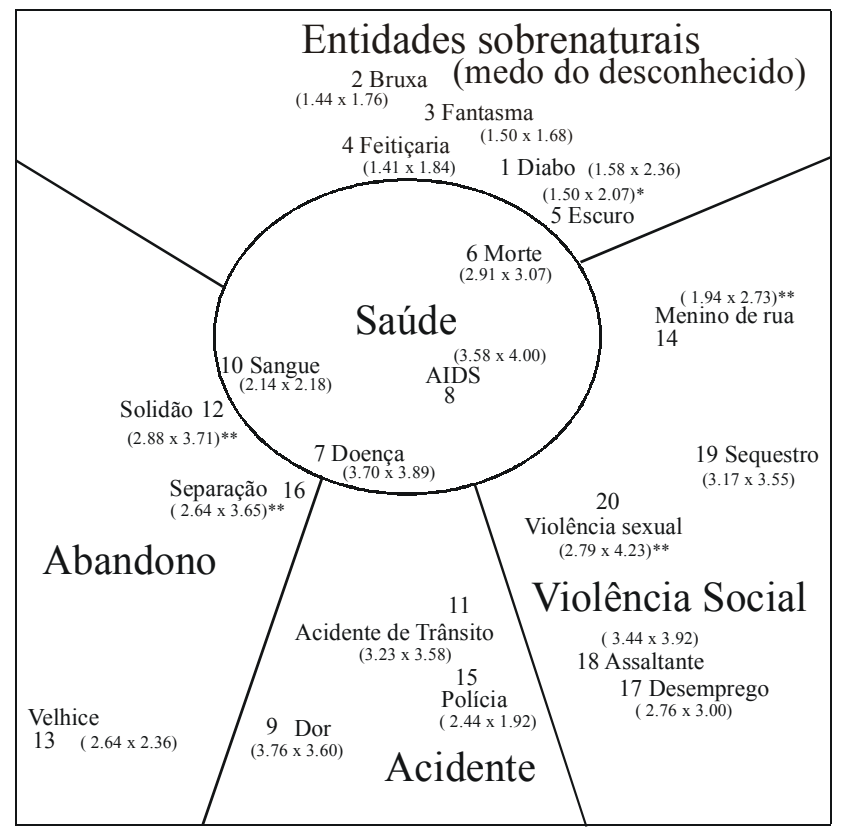

Em parenteses (média dos homens $\mathrm{x}$ média das mulheres)

$*=p<.05 ; * *=p<.01$ Coeficiente de alienação .16

Figura 3. Análise SSA de toda a amostra (Coordenada 1 vs. Coordenada 2 da solução tridimensional)

último podemos dizer que ele é um item limítrofe destas duas regiões. O mesmo se passa com o item "dor", que se põe nos limites das regiões Abandono e Acidente, mostrando a dupla conotação deste, a dor física e a dor psíquica (abstrata). Os itens "sangue" e "doença" encontram-se muito próximos das regiões Abandono ("velhice", "solidão" e "separação" são os itens que constituem esta região), sendo esta proximidade maior com os itens "solidão" e "separação", e Acidente (composta pelos itens "polícia", "acidente de trânsito" e "dor"), enquanto o item "AIDS" encontra-se atraído pela região Violência Social, principalmente pelo item "violência sexual" (esta região é formada pelos itens "menino de rua", "seqüestro", "violência sexual", "assaltante", "desemprego"). O item "menino de rua" possui uma proximidade muito forte com a região Entidades Sobrenaturais, em específico com o item "escuro". Para melhor entendermos, na classificação livre isso pode ser justificado quando um dos sujeitos dizia que "o menino de rua está no escuro porque ele está perdido nas ruas," tendo este escuro uma idéia de desamparo e desorientação.

Se analisarmos cada grupo separadamente veremos que os itens que têm maior correlação entre si são os da região Entidades Sobrenaturais (ver Tabela 3). E disso podemos concluir que as pessoas que têm medo de um dos itens desta região provavelmente temerá os demais, ou o oposto, quem não tiver medo de um destes itens também não terá medo do restante.

Para verificar a existência destas cinco dimensões através de outra análise estatística, os dados da classificação dirigida foram submetidos a uma análise fatorial (rotation varimax). Foram isolados cinco fatores explicando $61.4 \%$ da variância. Na Tabela 3 descrevem-se as saturações dos itens nos cinco fatores (apenas os retidos em negrito com coeficiente superior a .30). Estes são idênticos às cinco regiões descritas na análise SSA. A análise da consistência interna dos itens por cada sub-escala (fatores) encontra-se descrita na Tabela 4.

Por último, para verificarmos a existência de eventuais diferenças entre os diversos tipos de medos tendo como base a análise SSA, foram calculadas as médias de cada um dos

Tabela 3. Resultado da análise fatorial da escala com respectivas saturações dos itens nos dois fatores encontrados

\begin{tabular}{|c|c|c|c|c|c|c|c|c|c|c|}
\hline Itens & Com. & CT & Eigenv. \% & Var. $\%$ & Acu. & F.1 & F.2 & F.3 & F.4 & F.5 \\
\hline 01. Diabo & .59 & .44 & 5.61 & 28.1 & 28.1 & .64 & .38 & -.01 & .00 & .01 \\
\hline 02. Bruxa & .85 & .44 & 2.51 & 12.6 & 40.7 & .92 & .05 & .05 & .00 & .05 \\
\hline 03. Fantasma & .75 & .51 & 1.55 & 7.8 & 48.4 & .79 & -.01 & .36 & .07 & -.00 \\
\hline 04. Feitiçaria & .72 & .50 & 1.33 & 6.7 & 55.1 & .82 & .04 & .12 & .11 & .13 \\
\hline 05. Escuro & .45 & .49 & 1.26 & 6.3 & 61.4 & .45 & .14 & .48 & .04 & .06 \\
\hline 06. Morte & .67 & .37 & & & & .14 & .16 & .79 & -.06 & -.10 \\
\hline 07. Doença & .73 & .55 & & & & .01 & .15 & .74 & .18 & .36 \\
\hline 08. AIDS & .51 & .57 & & & & .21 & .29 & .56 & .23 & .15 \\
\hline 09. Dor & .60 & .40 & & & & -.11 & .08 & .21 & .57 & .45 \\
\hline 10. Sangue & .51 & .42 & & & & .29 & -.16 & .40 & .45 & .12 \\
\hline 11. Ac. trans & .62 & .55 & & & & .13 & .23 & .16 & .69 & .20 \\
\hline 12. Solidão & .64 & .43 & & & & .29 & .15 & .06 & -.01 & .73 \\
\hline 13. Velhice & .42 & .12 & & & & -.19 & -.15 & .09 & .25 & .53 \\
\hline 14. Men. rua & .30 & .38 & & & & .35 & .38 & .14 & .00 & .11 \\
\hline 15. Polícia & .53 & .21 & & & & .05 & .04 & -.04 & .71 & -.12 \\
\hline 16. Separação & .65 & .42 & & & & .18 & .24 & .04 & -.00 & .75 \\
\hline 17. Desemprego & .70 & .49 & & & & -.02 & .53 & .04 & .63 & .12 \\
\hline 18. Assaltante & .61 & .50 & & & & -.06 & .66 & .20 & .15 & .32 \\
\hline 19. Sequestro & .68 & .50 & & & & .31 & .69 & .02 & .31 & -.11 \\
\hline 20. Viol. sex. & .66 & .48 & & & & .08 & .76 & .24 & .01 & .07 \\
\hline
\end{tabular}

F.1: Fator 1 - Entidades sobrenaturais; F.2: Fator 2 - Violência Social; F.3: Fator 3 - Saúde; F.4: Fator 4 - Acidente; F.5: Fator 5 - Abandono. Com.: Comunalidade; CT: Correlação total do item; 
Tabela 4. Resultado da análise de consistência interna (reliability)* dos 5 fatores encontrados na análise fatorial

\begin{tabular}{|c|c|c|c|c|c|}
\hline Itens/Fatores & $\begin{array}{l}\text { Média da escala se } \\
\text { item é retirado }\end{array}$ & $\begin{array}{l}\text { Variância corrigida } \\
\text { se item é corrigido }\end{array}$ & $\begin{array}{c}\text { Correlação total do } \\
\text { item }\end{array}$ & $\begin{array}{c}\text { Quadrado da } \\
\text { correlação múltipla }\end{array}$ & $\begin{array}{l}\text { Valor de Alpha se } \\
\text { item é retirado }\end{array}$ \\
\hline \multicolumn{6}{|c|}{ Fator 1: Entidades sobrenaturais (medo do desconhecido); Alpha: .82 Alpha estandardizado .84} \\
\hline 01. Diabo & 6.65 & 11.47 & .57 & .36 & .81 \\
\hline 02. Bruxa & 7.04 & 12.47 & .77 & .76 & .75 \\
\hline 03. Fantasma & 7.05 & 13.15 & .68 & .60 & .77 \\
\hline 04. Feitiçaria & 7.01 & 12.29 & .72 & .65 & .76 \\
\hline 05. Escuro & 6.85 & 13.88 & .43 & .24 & .84 \\
\hline \multicolumn{6}{|c|}{ Fator 2: Violência Social; Alpha: .74 Alpha estandardizado .75} \\
\hline 14. Men.de rua & 13.51 & 16.39 & .33 & .15 & .75 \\
\hline 17. Desempr. & 12.98 & 14.18 & .51 & .30 & .69 \\
\hline 18. Assaltante & 12.18 & 15.67 & .54 & .30 & .69 \\
\hline 19. Seqüestro & 12.50 & 12.67 & 62 & .41 & .64 \\
\hline 20. Viol. Sexual & 12.31 & 13.68 & .53 & .33 & .68 \\
\hline \multicolumn{6}{|c|}{ Fator 3: Saúde; Alpha: .72 Alpha estandardizado .73} \\
\hline 05. Escuro & 12.78 & 16.12 & .47 & .24 & .69 \\
\hline 06. Morte & 11.58 & 14.19 & .47 & .26 & .68 \\
\hline 07. Doença & 10.78 & 14.34 & .59 & .39 & .64 \\
\hline 08. AIDS & 10.78 & 13.33 & .52 & .33 & .66 \\
\hline 10. Sangue & 12.42 & 16.56 & .39 & .18 & .71 \\
\hline \multicolumn{6}{|c|}{ Fator 4: Acidente; Alpha: .71 Alpha estandardizado .71 } \\
\hline 09. Dor & 10.63 & 12.48 & .48 & .25 & .66 \\
\hline 10. Sangue & 12.15 & 13.20 & .34 & .12 & .71 \\
\hline 11. Ac. transito & 10.90 & 11.18 & .62 & .42 & .60 \\
\hline 15. Policia & 12.15 & 12.77 & .36 & .15 & .71 \\
\hline 17. Desempr. & 11.43 & 10.81 & .54 & .37 & .63 \\
\hline \multicolumn{6}{|c|}{ Fator 5: Abandono; Alpha: .61 Alpha estandardizado .62 } \\
\hline 12. Solidão & 9.36 & 7.2 & .43 & .27 & .50 \\
\hline 13. Velhice & 10.18 & 8.4 & .27 & .09 & .63 \\
\hline 16. Separação & 9.50 & 7.2 & .50 & .33 & .45 \\
\hline 09. Dor & 9.00 & 8.6 & .38 & .17 & .55 \\
\hline
\end{tabular}

* O Alpha considerando todos os itens foi .8529;

Tabela 5. Médias e desvios-padrões dos tipos de medos de acordo com sexo

\begin{tabular}{lcccccc}
\hline \multirow{2}{*}{ Tipo de Medos } & \multicolumn{2}{c}{ Homens } & \multicolumn{2}{c}{ Mulheres } & \multicolumn{2}{c}{ Total } \\
\cline { 2 - 7 } & Média & DP & Média & DP & Média & DP \\
\hline Entidades & 1.48 & .62 & .95 & 1.00 & 1.73 & .87 \\
Sobrenaturais & & & & & & \\
Abandono & 2.72 & .96 & 3.25 & .94 & 3.00 & .98 \\
Acidentes & 3.15 & .86 & 3.03 & .93 & 3.09 & .89 \\
Violência Social & 2.82 & .96 & 3.49 & .76 & 3.17 & .92 \\
Saúde & 3.08 & .99 & 3.29 & 1.01 & 3.19 & 1.00 \\
Total & 3.00 & .88 & 2.65 & .93 & 2.83 & .93 \\
\hline
\end{tabular}

grupos de medos, tanto dos homens como das mulheres. $\mathrm{Na}$ Tabela 5 estão apresentadas estas médias. Observa-se claramente como o grupo de itens Entidades Sobrenaturais apresentou médias mais baixas em ambos os sexos em relação aos outros tipos de medos. Observa-se também a média superior apresentada pelas mulheres em todos os tipos de medos à exceção do medo, Acidentes e Entidades Sobrenaturais.

Para verificar estatisticamente estas diferenças, os dados foram submetidos a uma Análise de Variância tendo (2:
Masculino e Feminino) como variável "entre" e Tipos de Medos (5: Entidades Sobrenaturais, Abandono, Acidentes, Violência Social e Saúde) como variável “intra”. O julgamento em relação a cada tipo de medo era considerado como variável dependente. Encontrou-se um efeito principal de Sexo $[F(1,70)=5.44 ; p<.023]$, Tipo de Medo $[F(4,280)=$ $50.83 ; p<.0001]$ e um efeito interativo Sexo x Tipo de Medo $[F(4,280)=3.05 ; p<.017]$.

O efeito principal da variável Sexo confirma o nível de medo mais acentuado nas mulheres (3.00) do que nos homens (2.65). Comparações a posteriori (Teste de Tukey) das diferenças entre as médias nos cinco Tipos de Medos indicaram que, dentre todos os tipos de medos, o grupo Entidades Sobrenaturais foi o tipo de medo menos ameaçador em relação aos outros $(p<.01)$. O mesmo tipo de análise do efeito interativo Tipos de Medos x Sexo (Figura 4) indicou que ao compararmos os dois grupos de sujeitos por cada tipo de medo somente em dois tipos de medos - Abandono $(p<.05)$ e Violência Social $(p<.01)$ - as mulheres apresentaram médias estatisticamente mais altas do que os homens. Comparações entre os cinco tipos de medos por cada sexo indicaram que entre todos os tipos de medos o grupo Entidades Sobrenaturais foi o menos ameaçador em relação aos 
outros tipos, tanto para os homens como para as mulheres ( $p$ $<.01)$. Nenhuma diferença estatisticamente significativa foi observada entre os outros quatro tipos de medos.

\section{Discussão}

O interesse principal desta investigação foi analisar a organização estrutural de representações sociais do medo em adultos e o nível de consenso destas representações em função da variável gênero para assim explorar novas técnicas de avaliação (técnica não-verbal das classificações múltiplas) e de análise de dados (MSA e SSA). A esse respeito, podemos afirmar que praticamente não existem, aqui no Brasil, pesquisas adotando tais procedimentos. Como também não se tem conhecimento da existência de nenhum instrumento, em língua portuguesa, para medir medos gerais ou específicos em crianças ou em outras populações. Há dificuldade, portanto, de se encontrar instrumentos que possuam validade e fidedignidade (Neri, 1987).

Sendo assim, o objetivo do presente trabalho era identificar elementos consensuais e avaliar o nível de consenso de diferentes grupos de adultos presentes na representação social do medo entre os gêneros. É importante relembrar que, do ponto de vista teórico, um problema muito sério na pesquisa em representações sociais é a coleta de dados a partir do indivíduo, da qual se inferem conclusões gerais a nível social. Em outras palavras, o consenso ou os elementos compartilhados numa representação de determinado objeto, em um determinado grupo, não são questionados nem submetidos a processos rigorosos de verificação. Precisamos adotar formas de verificações mais objetivas a fim de legitimar a origem de uma representação a determinado grupo, desvelando seus enraizamentos sociais. Sendo o consenso a base dos processos de comunicação, a técnica não-verbal das classificações múltiplas apresenta-se como privilegiada às verificações objetivas que buscamos.

Além do mais, este problema da verificação empírica do consenso que uma representação possui em um determinado grupo impõe-se tanto em pesquisas que avaliam um único grupo de sujeitos como em pesquisas que comparam representações de dois ou mais grupos através de análises de variância (e.g., Hewstone et al, 1982). Em ambos os casos, de fato, o consenso intra-grupo ou entre-grupos não é questionado, mas considerado como ponto pacífico.

A fim de contextualizar as interpretações a seguir, reflitamos um pouco sobre o cotidiano de relações sociais em que as representações são forjadas. Vemos todos os dias, nos jornais, rádio e televisão, notícias violentas: homicídios, estupros, seqüestros etc. É amplamente noticiado também o descaso institucional com a saúde pública bem como as limitações da medicina para solucionar novas doenças que surgem. Outra gama de informações relaciona-se à falta de segurança e ao crescimento da miséria e do desemprego. Tal conjunto de acontecimentos é apresentado a todos os cidadãos da aldeia global pelos meios de comunicação de massa, contribuindo para o estresse característico desta "miniaturização" do mundo proporcionada pela tecnologia.
As representações sociais estão imersas neste movimento, em meio a trocas de idéias e imagens, em eventos diversos de comunicação que as estruturam e sustentam - com as quais os indivíduos negociam seus pertences através da coerência com os consensos dos grupos. Evidencia-se, neste mecanismo de busca do consenso, a conotação psicossocial das representações: se, por um lado, os indivíduos mobilizam-se cognitiva e afetivamente na direção do consenso, ao mesmo tempo a situação social pressiona-os à inferência.

Vimos, nas análises multidimensionais realizadas, que podemos distinguir claramente quatro grandes grupos denominados respectivamente de: Entidades Sobrenaturais, Violência Social, Abandono e Saúde. No primeiro, encontramos os seguintes itens: "diabo", "fantasma", "bruxa", "feitiçaria" e "escuro". Em ambas as análises, estes itens encontram-se bastante correlacionados entre si quando comparados aos demais. E pelas justificativas que os sujeitos deram para os agrupamentos, durante a classificação livre, podemos dizer que o critério norteador mais evidente para as explicações destes elementos são imaginários, pertencentes ao "sobrenatural", e permeados de conotação negativa, de "coisas ruins" ("a maldade", "coisa do diabo", "satanismo"). São elementos que "vão causar medo", ou não, em função da "crença de cada pessoa". Para "as pessoas que crêem" nestas coisas, estas "acham que elas acontecem" de preferência "no escuro" (à noite). Porém algumas dizem não acreditar, alegando serem estes "medos de criança" e que "dependem da crença que as pessoas possuem" a respeito. Muitas associaram estes itens com a morte, justificando assim a proximidade deste grupo com o de Saúde. Se observarmos a projeção para a amostra toda (a do SSA), podemos ver a proximidade dos itens morte e escuro. Comparações entre as médias apontaram que esta é a região que menos causa medos, tanto nos homens como nas mulheres.

No grupo Violência Social temos os itens "menino de rua", "seqüestro", "violência sexual", "assaltante", "desemprego", "polícia" e "acidente de transito". Neste a estrutura político-econômico-social vem como a "causadora" destas questões. Para a maioria desta pesquisa, o "desemprego faz com que as pessoas passem a praticar seqüestros, assalto", geralmente "são pessoas marginalizadas pela sociedade". O "desemprego" também "pode levar ao aumento do número de crianças que precisam ir para as ruas trabalhar" e "acabam se envolvendo com a criminalidade"; sendo assim, ele é a "causa" evidente da marginalidade e, neste contexto, a polícia teria o papel de manter a ordem social. Por outro lado, ela também é vista como propiciadora da violência, pois também "praticam atos agressivos quando matam ou maltratam os meninos de rua". O temor com relação à violência social é significativamente maior nas mulheres, principalmente quando se questiona a violência sexual.

Com relação ao item "acidente de trânsito" podemos dizer que, apesar de ele também envolver a polícia numa questão de ordem no trânsito, está mais relacionado com o fator de lesão corporal e não tanto como uma questão decorrente das estruturas de relações sociais. "Acidente de trânsito" lembra aos sujeitos a idéia de "dor", "sangue" e a possibilidade 
de uma morte. Outro aspecto que aproxima estes dois fatores é o fato de que tanto a "violência sexual" como o "sangue" podem ser vias de transmissão da "AIDS", de acordo com as falas dos sujeitos: "sangue pode transmitir a AIDS".

Vimos também que o item "menino de rua" encontra-se (ver MSA) próximo ao fator Entidades Sobrenaturais, isso porque foram relacionados ao item "escuro", tendo este o sentido de "estar perdido", "sem rumo", "perdidos na noite", "na solidão".

Na região Abandono encontramos os itens "velhice", "solidão" e "separação". Os sujeitos, de modo geral, vêem a velhice como "algo solitário", e a solidão como "uma morte". "A morte é uma separação" que pode "levar à solidão": "as doenças podem fazer com que nos sintamos sozinhos". Segundo os nossos sujeitos, na velhice as pessoas estão mais propícias a enfermidades, o que deixa a idéia de que estão mais próximas da morte que as pessoas mais jovens. A separação pode trazer solidão, e na velhice as pessoas costumam sentirem-se sós. São coisas como estas que causam medo, e vimos, pela classificação livre, que o item "medo" encontrase próximo desta região - Abandono, conjuntamente com a região Saúde. A "morte é o fim da vida" e a velhice é vista como "muito próxima da morte", as "doenças também podem levar à morte" e isso sustenta a aproximação entre os itens das regiões Abandono e Saúde. Vale ressaltar que as mulheres atemorizam-se mais significativamente que os homens com os itens da região Abandono: elas não querem passar por essas "situações que são desagradáveis".

Na região Saúde encontramos os seguintes itens: "AIDS", "morte", "doença", "sangue" e "dor". A "AIDS" é uma doença que "causa pavor" em algumas pessoas e que "leva à morte"; "é causadora de muito sofrimento, dor" - seja ela física, devido aos comprometimentos orgânicos decorrentes, seja ela psíquica, causada pela idéia de isolamento e solidão: "ela pode ser transmitida tanto pela violência sexual como pelo sangue", e isso justifica a proximidade entre as regiões Violência Social e Saúde. Os itens da região Saúde são os mais fortemente associados com a morte como também os da região Entidades Sobrenaturais e, sobre eles, os sujeitos disseram que "são coisas que causam angústia e medo", pelas quais "ninguém quer passar".

Entre os itens de Saúde, o da AIDS se encontra na parte mais central. Portanto, o item AIDS, ao ser o mais central da região mais central, desempenha um papel modulador em relação a todos os outros, apresentando a mais alta correlação positiva com todos os demais. É como se a preocupação com a saúde em geral e, mais especificamente, com a AIDS (contágio x prevenção), desempenhasse um papel central para explicar os outros tipos de medos. Esta constatação tem importantes fins aplicativos: qualquer tipo de ação visando reduzir o nível de estresse e medo da população seria muito mais eficaz se visasse reduzir os medos relativos a questões da saúde em geral e, em específico, com a ameaça onipresente da AIDS. Portanto, poder-se-ia até falar na Saúde, especificamente na AIDS, como um elemento consensual do medo na sociedade contemporânea. Os estudos recentes sobre representações sociais da AIDS demonstram, invariantemente, a presença do medo diante desta doença, o qual vai se delineando em diferentes formas ansiogênicas nas enunciações dos sujeitos, fazendo-os mesmo perder o nexo do que tentam dizer sobre o assunto (Carvalho, 1998; Jodelet \& Madeira, 1998; Madeira \& Carvalho, 1998).

Considerados em seu conjunto, os resultados das projeções dos dois grupos de adultos, homens e mulheres apresentam os mesmos tipos de regionalização dos itens e um mesmo tipo de partição entre as regiões. As várias regiões apresentam elementos e características qualitativamente diferentes, cada região ocupando uma direção diferente no espaço da projeção MSA, que emana de um mesmo ponto comum de origem - o item "medo".

Entretanto, apesar de haver estas configurações com estruturas muito parecidas, existem, ao mesmo tempo, diferenças específicas refletindo a experiência de cada grupo, sendo que tais diferenças não muito acentuadas, o que obviamente é de se esperar pelas características da experiência de vida similares entre os dois grupos de adultos.

Assim, apesar das diferenças detectadas, não é possível afirmar a existência de núcleos diferentes para as representações sociais do medo entre estes dois grupos. Embora o nível de consenso desta representação social tenha sido avaliado empiricamente, naturalmente esta constatação precisa ser considerada com cautela, pela limitação que caracteriza este estudo devido ao fato de ser uma investigação isolada de representação social do medo, utilizando técnicas de avaliação que merecem ulteriores confirmações empíricas. São necessários estudos com outras populações, como também com outros métodos empíricos, focalizando tanto aspectos quantitativos como qualitativos. Esta nossa reflexão metodológica surge da necessidade de determinar e avaliar com precisão o tipo de metodologia utilizada no estudo das representações sociais, especialmente se são comparadas amostras com experiências socioculturais diferentes.

Entretanto, apesar das limitações, conseqüência do caráter exploratório desta investigação, foi possível tecer algumas considerações de ordem mais geral sobre os tipos de medos. O dado mais interessante que surge a partir da análise destes resultados é o tipo de estrutura muito parecida que foi encontrada entre estes dois grupos de sujeitos(estrutura polar na análise MSA).

O que foi constatado nesta investigação constitui um primeiro passo para uma análise da representação social de uma emoção: o medo. A abordagem adotada, ao mesmo tempo quantitativa e qualitativa, baseada em técnicas de categorizações, permitiu-nos reconstruir uma "trama de base", apontando-nos direções para o planejamento de futuras investigações nesta mesma área.

\section{Referências}

Ades, C. (1993). Um assunto emocional. Curso de Psicologia Experimental II. Instituto de Psicologia, USP.

Ainsworth, S. (1981). O Poder Emocional Positivo: Como governar seus sentimentos. São Paulo: Cultrix. 
Bauer, D.H. (1976). An exploratory study of developmental changes in children's fears. Journal of Child Psychology and Psychiatry, 17, 69-74.

Canter, D. \& Comber, M. (1985). A multivariate approach to multiple sorting. Em Sequence Analysis: Surrey Conferences on Sociological Theory and Method - II. Aldershot: Gower.

Carvalho, M. R. (1998). Eu confio, tu prevines, nós contraímos: Uma psico(lógica) (im)permeável à informação! Em D. Jodelet e M. Madeira (Org.), AIDS e Representações Sociais: À busca de sentidos (pp. 89-94). Natal: EDUFRN.

Dantas, Heloysa (1992) Do ato motor ao ato mental: a gênese da inteligência segundo Wallon. Em Y. de La Taille (Org.), Piaget, Vygotsky, Wallon: Teorias psicogenéticas em discussão (pp. 3546). São Paulo: Summus.

Dong, Q., Yang, B. \& Ollendick, T.H. (1993). Fears in Chinese Children and Adolescents and Theirs Relations to Anxiety and Depression. Journal of Child Psychology and Psychiatry, 35, 351-363.

Eckman, P. (1975). Unmasking the face. New Jersey: Prentice Hall.

Fonseca, A.C. (1993). Medo em Crianças e adolescentes: Um estudo sobre a população portuguesa. Revista Portuguesa de Pedagogia, 22, 75-92.

Galli, I \& Nigro, G. (1986). La rappresentazione sociale del potere in un campione di studenti universitari. Psicologia e Societá, 11(1), 20-32.

Groat, L. (1982). Meaning in post-modern architecture: An examination using the multiple sorting task. Journal of Environmental Psychology, 2(3), 3-22.

Hallowell, A.I. (1938). Fear and anxiety as cultural and individual variables in a primitive society. Journal of Social Psychology, 9, 25-42.

Harris, P. (1989). Children and emotion: The development of psychological understanding. Oxford: Blackwell.

Hersen, M. (1973). Self-Assessment of Fear. Behavior Therapy, 4, 241-257.

Hewston, M., Jaspars, J. \& Lallje, M. (1982). Social representations, social attributions and social identity: The intergroup images of public and comprehensive schoolboys. European Journal of Social Psychology, 12, 241-271.

Jodelet, D. \& Madeira, M. (1998). (Orgs.). AIDS e representações sociais: À busca de sentidos. Natal: EDUFRN.

Jodelet, Denise (1989). Les Représentacions Sociales: Un domaine en expansion. Em D. Jodelet (Org.), Les Représentacions sociales (pp. 31-61). Paris: PUF.

King, N.J., Gullone, E. \& Ollendick, T.H. (1992). Manifest anxiety and fearfulness in children and adolescents. Journal of $\mathrm{Ge}$ netic Pychology, 153, 63-74.

King, N.J., Hamilton, D.I. \& Ollendick, T.H. (1988). Children's phobias: a behavioural perspective. Chichester: Wiley.

King, N.J., Ollier, K., Iacuone, R., Schuster, S., Bays, K., Gullone, E. \& Ollendick, T.H. (1989). Fears of children and adolescents: a cross-sectional Australian study using the Revised Fear Survey Schedule for Children. Journal of Psychology and Psychiatry, 30, 775-784.

Le Bouedec, G. (1979). Contribution à la méthodologie d'étude des représentations sociales. Étude de la participation. Thèse de Doctorat, Université Catholique de Louvain.
Madeira, M.C. \& M.R. Carvalho. (1998). Sexe ef affectivité en temps du SIDA: La question de la prevention. Texto em CD-Rom acessível por "www.inrp.fr/acces/biennale/biennale.htm".

Mandler, G. (1982). The construction of emotion in the child. Em C.E. Izard (Org.), Measuring emotions in infants and children. Vol. 1, Cambridge, Mass.: Cambridge University Press.

Marks, I.M. (1987). Fears, phobias, and rituals. Oxford: Oxford University Press.

Monteiro, C.M.G. \& Roazzi, A. (1987). Representações sociais e o processo de classificações múltiplas. Algumas implicações metodológicas no estudo da estruturação socio-espacial da cidade. Psicologia Argumento, 7(6), 55-78.

Morris, R.J. \& Kratochwill, T.R. (1983). Treating children's fears and phobias. New York: Pergamon Press.

Moscovici, S. (1984). The phenomenon of social representation. In R. Farr \& S. Moscovici (Orgs.), Social Representation. Cambridge: Cambridge University Press.

Moscovici, S. (1978). A Representação Social da Psicanálise. Rio de Janeiro: Zahar Editora.

Neri, A.L.O. (1987). O Inventário Sheppard para medida de atitudes em relação à velhice e sua adaptação para o português. Estudos de Psicologia, 3(1,2), 23-42.

Nigro, G. \& Galli, I. (1988). La rappresentazione sociale della paura in soggetti in etá evolutiva: Primi rilievi. Psicologia e Societá, 13(1), 57-68.

Ollendick, T.H. (1979). Fear reduction techniques with children. Em M. Hersen, R.M. Eisler \& P.M. Miller (Orgs.), Progress in behavior modification, Vol. 8 (pp.127-168). New York: Academic Press.

Ollendick, T.H. (1983). Reliability and validity of the Revised Fear Survey Schedule for Children (FSSC-R). Behaviour Research Therapy, 21, 658-692.

Ollendick, T.H. \& King, N.J. (1991). Origins of childhood fears: an evaluation of Rachaman's theory of fear acquisition. Behavior Research Therapy, 29, 117-123.

Ollendick, T.H., King, N.J. \& Frary, R.B. (1989). Fears in clhidren and adolescents: reliability and generalizability across gender, age, and nationality. Behavior Research an Therapy, 27, 1926.

Ollendik, T.H., Yule, W. \& Ollier, K. (1990). Fears in British children and their relationship to manifest anxiety and depression. Journal of Child Psychology and Psychiatry, 32, 321-331.

Roazzi, A. (1995). Categorização, formação de conceitos e processos de construção de mundo: Procedimento de classificações múltiplas para o estudo de sistemas conceituais e sua forma de análise através de métodos de análise multidimensionais. $\mathrm{Ca}$ dernos de Psicologia, 1, 1-27.

Roazzi, A. (1997). Aportes teóricos: Psicologia Cognitiva. "Psicologia cognitiva e sua relação com a psicologia social" Trabalho apresentado na modalidade Mesa-Redonda no Encontro "Dez anos de Mestrado em Psicologia Social e da Personalidade - Psicologia: Estado da Arte e do Futuro", promovido pelo curso de Pós-graduação em psicologia Pontifícia Universidade Católica do Rio Grande do Sul, Porto Alegre, RS, 4 a 6 de Setembro de 1997.

Roazzi, A. (1999). Lar-doce-lar: Rainha ou rei? A representação da participação masculina nas tarefas domésticas e a lógica de sua 
distribuição em casais de nível sócio-econômico baixo. Arquivos Brasileiros de Psicologia, 51(4), 7-38

Roazzi, A. (2000). Pesquisa básica em psicologia cognitiva e sua relação com a psicologia social. Arquivos Brasileiros de Psicologia, 51(1), 23-54.

Roazzi, A. \& Monteiro, C.M.G. (1991). Social representation of the professional urban mobility and its implication for school failure. Anais do XIV International School Colloquium - Braga, Portugal. De 22 à 27 de Junho.

Roazzi, A. \& Monteiro, C.M.G. (1995). A representação social da mobilidade profissional em função de diferentes contextos urbanos e suas implicações para a evasão escolar. Arquivos Brasileiros de Psicologia, 47(3), 39-73.

Roazzi, A., Wilson, M. \& Federicci, F. (1995). Exploring the social representation of fear in children: A social class comparison. In Joop J. Hox, Peter Swanborn \& G.J. Mellemberg (Orgs.), Facet Theory: Theory and content. Zeist: SETOS.

Scherer, M.W. \& Nakamura, C.Y. (1968). A Fear Survey Schedule for Children (FSS-FC): a factor-analytic comparison with mani- fest anxiety (CMAS). Behavior Research and Therapy, 6, 173182.

Schiffman, S.S., Reynolds, M.L. \& Young, F.W. (1981). Introduction to multidimensional scaling. Theory, methods and applications. New York: Academic Press.

Shepard, R.N. (1962). The analysis of proximities: Multidimensional scaling with an unknown distance function, Psychometrika, 27, 125-139 (Parte 1), 219-246 (Parte 2).

Sherif, M. \& Sherif, C. (1969). Social Psychology. New York/Tokio: Harper \& Row.

Shye, S. (1978). Theory construction and data analysis in the behavioural sciences. São Francisco: Jossey-Bass Publishers.

Souza, Jorge de, (1988). Métodos Estatísticos nas Ciências Psicossociais. Vol. V-Métodos de escalagem psicossocial: Uni e Multidimensional. Brasília: Thesaurus.

Tajfel, H.C. (1981). Human groups and social categories. Cambridge: Cambridge University Press.

Vygotsky, L. (1934). Thought and Language. Boston, M.A.: MIT Press.
Recebido em 07.07.1999

Primeira decisão editorial em 10.08.2002

Versão final em 10.08.2002

Aceito em 02.10.2002 